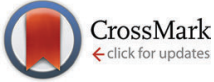

Cite this: Phys. Chem. Chem. Phys., 2015, 17, 9074

Received 23rd January 2015, Accepted 26th February 2015 DOI: $10.1039 / c 5 c p 00430 f$

www.rsc.org/pccp

\title{
Engineering of pyranose dehydrogenase for application to enzymatic anodes in biofuel cells $\dagger$
}

\author{
Maria E. Yakovleva, $\ddagger^{\mathrm{a}}$ Christoph Gonaus, $\ddagger^{\mathrm{b}}$ Katharina Schropp, ${ }^{\text {ab }}$ Peter ÓConghaile, ${ }^{\mathrm{c}}$ \\ Dónal Leech, ${ }^{c}$ Clemens K. Peterbauer $^{\mathrm{b}}$ and Lo Gorton*a
}

\begin{abstract}
In the search for improved glucose oxidising enzymes for biofuel cells, a number of Agaricus meleagris (Am) pyranose dehydrogenase mutants (mPDHs) exhibiting different degrees of glycosylation were produced using site-directed mutagenesis and electrochemically characterised. The response of electrodes modified with different $\mathrm{mPDHs}$ is compared in a mediated electron transfer mode, where the electrodes are modified with each of the mutants covalently attached to redox polymers based on polyvinylimidazole-bound osmium complexes using a cross-linking agent. Coating of each of the enzymes onto the graphite electrode surface is also used to screen for their capacity for direct electron transfer. The double mutant PDH exhibits the highest response to glucose at physiological $\mathrm{pH}$ in both direct and mediated electron transfer modes, producing a $J_{\max }$ of $\approx 800 \mu \mathrm{A} \mathrm{cm}^{-2}$ at room temperature and when "wired" to the Os-polymer having the highest formal potential. From the results obtained the double $\mathrm{mPDH}$ is proposed as the most suitable candidate for application to bioanode fabrication.
\end{abstract}

\section{Introduction}

An enzymatic biofuel cell (EBFC) is a specific class of fuel cells, which converts the energy of enzymatic redox reactions into electrical energy as long as fuel is supplied to it. The development of EBFCs became more extensive during the last few years due to their beneficial properties. Compared to conventional fuel cells, EBFCs can operate in physiological conditions and utilise fuels and oxidants present in vivo even at low concentrations. ${ }^{1-9}$ These features make EBFCs applicable for construction of miniaturised implantable devices, which can be used as continuous power supplies with the energy derived from physiological sugars.

An obvious example of such a device would be an EBFC powering a cardiac pacemaker - medical devices currently powered by lithiumiodine batteries invented by Wilson Greatbatch and his team in 1972, with a life time of about 10 years. ${ }^{10}$ EBFCs can also be applied as implantable self-powered sensors, for instance in monitoring of the glucose concentration in blood for diabetes management. ${ }^{11}$

One of the reasons why EBFCs still did not yet reach the market is the low power output, which is directly related to the

\footnotetext{
${ }^{a}$ Department of Analytical Chemistry/Biochemistry and Structural Biology, Lund University, PO Box 124, SE-221 00 Lund, Sweden. E-mail:lo.gorton@biochemistry.lu.se

${ }^{b}$ Department of Food Sciences and Technology, BOKU-University of Natural Resources and Applied Life Sciences, Muthgasse 18, A-1190 Wien, Austria ${ }^{c}$ School of Chemistry, National University of Ireland Galway, University Road, Galway, Ireland

$\dagger$ Electronic supplementary information (ESI) available: Information concerning purification of mutant PDHs. See DOI: 10.1039/c5cp00430f

\$ These authors contributed equally.
}

current generated in the anodic part, where sugar is oxidised at the anode, onto which the biocatalyst is immobilised, and the cathodic part, where oxygen is reduced. In order to produce an EBFC with a sufficient power capacity it is important to maximise the current density generated in both parts of the cell. This can be done by a variety of methods.

One of the most efficient ways is to improve the electrical communication between the redox enzyme and the electrode, which to a large degree determines the current output. This can be done by "wiring" the enzyme to osmium redox polymers, which will facilitate the electron transfer between the enzyme's active site and electrode surface. ${ }^{12-16}$ Such an approach was demonstrated in a number of recent publications, where various oxidising enzymes were cross-linked with redox polymers based on polyvinylimidazole-bound osmium complexes in order to improve the current density of both bioanodes ${ }^{17-19}$ and biocathodes. ${ }^{20,21}$

Another way to increase the current output of the bioanode and the biocathode is to downsize the dimensions of the enzyme. ${ }^{22}$ This can be achieved by employing whole deglycosylated enzymes or by utilising separate enzyme domains responsible for the catalytic activity. By removing the carbohydrate shell from glycosylated redox enzymes it is possible to physically bring the enzyme's active site closer to the electrode surface or mediator matrix, which will increase the electron transfer rate according to the Marcus theory. ${ }^{23}$ This has been previously demonstrated for horseradish peroxidase (HRP), ${ }^{24,25}$ glucose oxidase (GOx), ${ }^{26,27}$ cellobiose dehydrogenase $(\mathrm{CDH})^{28,29}$ and pyranose dehydrogenase (PDH). ${ }^{30-32}$ Shao et al. proposed a bioanode based on the separately expressed deglycosylated dehydrogenase domain of $\mathrm{CDH}\left(\mathrm{DH}_{\mathrm{CDH}}\right){ }^{33,34}$ When using only 
$\mathrm{DH}_{\mathrm{CDH}}$ instead of the whole enzyme for construction of EBFCs, a greater load of the biocatalyst can be packed onto the electrode surface due to the smaller size of $\mathrm{DH}_{\mathrm{CDH}}$ resulting in higher currents. Downsizing the redox enzyme for improved current density was also demonstrated for deglycosylated $\mathrm{PDH}$, which spontaneously loses a part of its C-terminus and forms a fragmented product with excellent electrocatalytic performance. ${ }^{35}$

$\mathrm{PDH}$ (EC 1.1.99.29) is a glycosylated extracellular enzyme produced by a group of litter-degrading basidiomycete Agaricales. It is a monomeric enzyme, which carries one flavin adenine dinucleotide (FAD) prosthetic group covalently bound to the polypeptide chain of the protein ${ }^{36}$ in contrast to other glucose oxidising enzymes carrying their cofactor only through non-covalent linkages. PDH belongs to the glucose-methanol-choline oxidoreductase superfamily, ${ }^{37}$ which also includes GOx (EC 1.1.3.4), pyranose oxidase (POx, EC 1.1.3.10), and $\mathrm{CDH}$ (EC 1.1.99.18). ${ }^{38}$ In contrast to other members of the same family, which can only monooxidise sugars at the $\mathrm{C}-1$ position, $\mathrm{PDH}$ (as well as POx) is able to mono- and dioxidise a variety of substrates at the C-2 and/or C-3 to their corresponding aldonolactones, or (di)dehydrosugars (aldos(di)uloses) and it is thus anomerically insensitive. $^{36,39,40}$ Unlike many sugar oxidising oxidoreductases PDH does not show reactivity towards molecular oxygen but makes use of other electron acceptors/mediators instead. ${ }^{41}$ Together with a broad substrate tolerance and regioselectivity, this lack of electron donation to oxygen can be explained by a unique structure of the flavin pocket specific for the members of VAO [6-S-cysteinyl-8 $\alpha$ (N1-histidyl)-FAD] family. ${ }^{42}$ These three properties make the enzyme attractive for construction of EBFCs, where a broad substrate tolerance is not considered a disadvantage, the covalently bound cofactor increases the long-term stability of the enzyme in its immobilised state and the inability to utilise oxygen prevents competition with $\mathrm{O}_{2}$ as electron acceptor as well as any damaging effects of hydrogen peroxide, which is otherwise formed when oxygen-dependent oxidoreductases are employed (e.g., GOx or POx).

The suitability of $\mathrm{PDH}$ for bioanode fabrication was first demonstrated for naturally occurring glycosylated Agaricus meleagris enzyme when "wired" to osmium redox polymers on the surface of graphite electrodes. ${ }^{43}$ The electrodes modified with $\mathrm{PDH}$ showed a higher current response to glucose in flow-injection amperometry compared to those modified with GOx. It was possible to oxidise the substrate at potentials close to the formal potential of the enzyme in near-physiological conditions. ${ }^{18}$ However, low production levels of PDH purified from the natural source hindered widespread application of the enzyme for fabrication of EBFCs and other biotechnological purposes. The problem was solved by heterologous expression of the enzyme in several host organisms, of which Pichia pastoris was shown to be most suitable, resulting in production of active recombinant enzyme (recAm $\mathrm{PDH}$ ) with $30 \%$ glycosylation. ${ }^{44}$ A further step in engineering of recAmPDH was achieved through enzymatic deglycosylation of the overglycosylated enzyme, which resulted in improved electrocatalytical performance of deglycosylated PDH compared to its glycosylated analogue. ${ }^{30-32}$ Time-consuming and generally expensive production of enzymatically deglycosylated enzyme suggested that other approaches for engineering of $\mathrm{PDH}$ should be implemented. In the present study we utilise a novel approach for engineering $\mathrm{PDH}$, based on a recent report, ${ }^{35}$ as follows: asparagine residues $(\mathrm{N})$ carrying the glycan moieties in the enzyme were first assigned using MALDI-MS measurements in combination with endoglycosidase treatment and tryptic digestion. ${ }^{35}$ Three of the five possible glycosylation positions: $\mathrm{N}^{75}, \mathrm{~N}^{175}$ and $\mathrm{N}^{252}$ were confirmed to carry carbohydrate moieties. Using site-directed mutagenesis it was then possible to exchange glycosylated asparagine $(\mathrm{N})$ residues and express an enzyme in Pichia pastoris that lacks part of the glycosyl moiety. Two single mutant PDHs (mPDHs) (SM) with asparagine residues exchanged to glycine $(\mathrm{G}), \mathrm{N} 75 \mathrm{G}$, and glutamine $(\mathrm{Q})$, $\mathrm{N} 175 \mathrm{Q}$, one double mutant with $\mathrm{N}$ exchanged to $\mathrm{G}$ in $\mathrm{N}^{75}$ and to $\mathrm{Q}$ in $\mathrm{N}^{175}$ position (DM; N75G N175Q) and one triple mutant with $\mathrm{N}$ exchanged to $\mathrm{G}, \mathrm{Q}$ and $\mathrm{Q}$ in positions $\mathrm{N}^{75}, \mathrm{~N}^{175}$ and $\mathrm{N}^{252}$, respectively (TM; N75G N175Q N252Q) were produced. In the work described herein all four mutants were electrochemically "wired" to three polyvinylimidazole-bound osmium complexes with different formal potentials $\left(E^{\circ \prime}=140 \mathrm{mV}, 320 \mathrm{mV}\right.$ and $420 \mathrm{mV}$ $v s$. NHE) and the electrocatalytic properties of the enzyme electrodes studied using flow-injection amperometry and cyclic voltammetry. The mPDHs were also directly adsorbed onto the working electrodes in order to study their ability to directly communicate with the electrode surface in a mediator-less mode.

\section{Enzyme engineering}

Four mutant PDHs from Agaricus meleagris were recombinantly expressed in Pichia pastoris (volumetric activity $0.1-0.4 \mathrm{U} \mathrm{mL}^{-1}$; specific activity $0.3-3.7 \mathrm{U} \mathrm{mg}^{-1}$, protein concentration $0.03-0.8 \mathrm{mg}$ $\mathrm{mL}^{-1}$ ). The enzymes were stored at $-20{ }^{\circ} \mathrm{C}$ in order to preserve their catalytic activity and were slowly thawed on ice prior to analysis. The volumetric activity of the mutants was determined on a UV-2401 PC spectrophotometer (Shimadzu Deutschland $\mathrm{GmbH}$, Duisburg, Germany) at $20{ }^{\circ} \mathrm{C}$ in the presence of ferricenium $\left(\mathrm{Fc}^{+}\right)$as electron acceptor and glucose as substrate. ${ }^{45}$ One unit of enzyme activity was equal to the amount of enzyme required for reduction of $2 \mu \mathrm{mol}$ of $\mathrm{Fc}^{+}$per $1 \mathrm{~min}$ at $20^{\circ} \mathrm{C}$.

Oligonucleotides were synthesised by VBC Biotech (Vienna, Austria) and polymerase chain reactions were conducted in a BioRad (Hercules, CA, USA) C1000 Thermal Cycler. Molecular biology reagents were obtained from Thermo Scientific (Waltham, MA, USA) and used according to the manufacturer's recommendations. Chemically competent E. coli NEB5 $\alpha$ from New England Biolabs (Ipswich, MA, USA) was used for vector constructions and $P$. pastoris X33 from Invitrogen (Carlsbad, CA, USA) for expression. Chromatography resins were purchased from GE Healthcare (Little Chalfont, UK). Endo Hf (1000 $000 \mathrm{U} \mathrm{mL}^{-1} ; 232000 \mathrm{U} \mathrm{mg}^{-1}$ ) was supplied by New England Biolabs (Ipswich, MA, USA).

\section{Site saturation and site directed mutagenesis}

Numbering of amino acid residues refers to the mature protein starting with the sequence AITYQ. ${ }^{46}$ The site saturation mutagenesis library was created using Phusion PCR polymerase (Thermo Scientific) according to the manufacturer's recommendations and the oligonucleotide primers fwAmPDHN75 and rvAmPDHN75X 
(Table S1, ESI $\dagger$ ). Chemically competent E. coli NEB5 $\alpha$ was transformed with the DpnI digested amplicon. All transformants were washed from the plate surface with $5 \mathrm{~mL}$ of LB medium

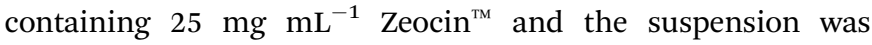
incubated for $90 \mathrm{~min}$ at $37{ }^{\circ} \mathrm{C}$ on a shaker. Recovered plasmids were linearised with MssI and electroporated into P. pastoris X33 according to the manufacturer's recommendations. Two hundred clones were picked for 96-deep-well plate expression as described by Sygmund et al. ${ }^{36}$ The supernatant was screened for enzymatic activity with $\mathrm{Fc}^{+}$and 2,6-dichlorophenolindophenol (DCIP) in 96-well plates.

Overlap extension PCR was used for site directed mutagenesis. Two amplicons were generated using Phusion DNA polymerase (Thermo Scientific) and one mutating oligonucleotide (Table S2, $\mathrm{ESI} \dagger$ ) with the complementary AOX oligonucleotide each $\left(3^{\prime} \mathrm{AOX}\right.$ : 5'-GCAAATGGCATTCTGACATCC-3'， 5'AOX: 5'-GACTGGTTCCAA TTGACAAG- $3^{\prime}$ ). In a subsequent polymerase chain reaction with $5^{\prime} \mathrm{AOX}$ and $3^{\prime} \mathrm{AOX}$ the two amplicons were fused. The resulting DNA fragment was ligated into the $X b a \mathrm{I}$ and $K p n I$ restriction sites of pPICZ-B. The vector was amplified in E. coli NEB5 $\alpha$, recovered and electroporated into $P$. pastoris according to the manufacturer's recommendations.

AmPDH1 [GeneBank: AY753307.1] glycosylation sites were previously predicted from the sequence in silico. Five consensus sites NXS/T are found, one $\left(\mathrm{N}^{313}\right)$ is ruled out by the presence of proline at the middle position, another one $\left(\mathrm{N}^{319}\right)$ was judged to have a low probability of glycosylation by the prediction software NetNGlyc 1.0. Positions $\mathrm{N}^{75}, \mathrm{~N}^{175}$ and $\mathrm{N}^{252}$ were since confirmed by mass spectrometry analysis of tryptic fragments. ${ }^{35}$ The locations of these sites, and of the additional site at $\mathrm{N}^{319}$, are shown in Fig. 1a, based on the AmPDH1 crystal structure. ${ }^{42} \mathrm{~N}^{319}$ is located in a surface cavity but the other sites are well exposed. $\mathrm{N}^{75}$ is located next to the largest active site access and close to the covalently bound catalytic co-factor FAD. $\mathrm{N}^{175}$ is situated on the other side of the active site access. The fragmentation site into the $\sim 46 \mathrm{kDa}$ and $\sim 20 \mathrm{kDa}$ fragments is between residues 416 and 417, positioned between $\mathrm{N}^{75}$ ( $\sim 34 \AA$ away) and $\mathrm{N}^{175}\left(\sim 24 \AA\right.$ away) (Fig. 1b). $\mathrm{N}^{252}$ is on the far side of the protein. $\mathrm{N}^{75}$ and $\mathrm{N}^{175}$ were selected for elimination due to the expected effect of reducing the distance from the active site and the FAD co-factor to the electrode surface when the enzyme is immobilised on the electrode. The third site, $\mathrm{N}^{252}$, was eliminated to additionally reduce the overall size of the enzyme. The AmPDH1 N75X site saturation mutagenesis library
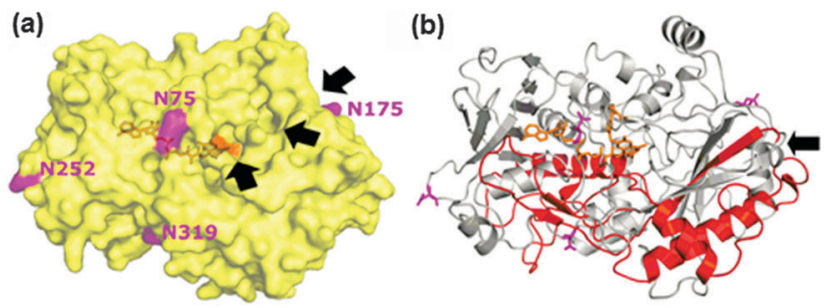

Fig. 1 AmPDH1 X-ray crystal structure (Tan et al. 2013), the FAD co-factor shown as stick structure and $N$-glycosylated Asn in purple. (a) Black arrows indicate access to the active site. (b) Cleavage position (arrow) of $\sim 46 \mathrm{kDa}$ (grey) and C-terminal $\sim 20 \mathrm{kDa}$ fragment (red). was created from Ampdh1 in pPICZ-B (Invitrogen, Life Technologies) with the primers fwAmPDHN75 and rvAmPDHN75X. 10\% of the screened clones expressed active $\mathrm{PDH}$ and were rescreened in triplicates, and 14 mutants with expression of active enzyme were sequenced. Half of the clones were wild type, while the others were mutated to N75G, Q, K or H. These four mutants were expressed in shake flasks with AmPDH1 wild type (wt) as positive control and purified in a simplified 2-step chromatography scheme (Table S1, $\mathrm{ESI} \dagger$ ). AmPDH1 N75G showed the best expression at almost wild type levels and was chosen for further study. The other $N$-glycosylation site mutants were constructed by site directed mutagenesis (Table S2, $\mathrm{ESI} \dagger$ ). AmPDH1 N75G/N175Q could be expressed in shake flasks to twice the volumetric activity of AmPDH1 N75G/N175G. Gln was therefore chosen as replacement for Asn at $\mathrm{N}^{175}$ and $\mathrm{N}^{252}$.

\section{Expression and purification of $A$. meleagris pyranose dehydrogenase 1 in $P$. pastoris}

Methanol induced expression in P. pastoris was done according to the Invitrogen "Pichia Fermentation Process Guidelines" in a $5 \mathrm{~L}$ stirred-tank bioreactor (MBR, Wetzikon, Switzerland) (see ESI $\dagger$ ).

The enzyme was purified from the harvested supernatant by salt precipitation $\left(\left(\mathrm{NH}_{4}\right)_{2} \mathrm{SO}_{4}\right)$ followed by hydrophobic interaction chromatography at room temperature $(750 \mathrm{~mL}$ of PhenylSepharose fast flow, $15 \mathrm{~mL} \mathrm{~min}^{-1}$ ). The eluted fractions of the enzyme were subjected to buffer exchange with Bis-Tris buffer (50 mM, pH 6.5) and subsequent anion exchange chromatography (60 mL of DEAE-Sepharose fast flow, $10 \mathrm{~mL} \mathrm{~min}^{-1}$ ) was conducted. The fractions with high enzyme activity were pooled and subjected to a second purification step, which included salt precipitation and hydrophobic interaction chromatography. The resulting fractions were pooled for highest specific activity, washed with sodium phosphate buffer (50 mM, pH 6.5) and concentrated by ultracentrifugation (10 kDa Amicon Ultra-15 Centrifugal Filter Units, Millipore Corp.). If necessary, the resulting enzyme solution was further purified by gel filtration $(180 \mathrm{~mL}$ of Superose12, $1 \mathrm{~mL} \mathrm{~min}^{-1}$ ). Purified and concentrated enzyme solutions were stored at $-20{ }^{\circ} \mathrm{C}$.

The recombinant expression of $\mathrm{N}$-glycosylation site mutants and the wt enzyme were compared in simultaneous expression in an Infors HT Multifors $6 \times 0.5 \mathrm{~L}$ bioreactor system, according to the Invitrogen "Pichia Fermentation Process Guidelines". Wet biomass, protein concentration and enzyme activity at standard conditions were determined (see ESI $\dagger$ ).

\section{Expression of AmPDH1 $\mathrm{N}$-glycosylation mutants}

The single mutant N75G and the multiple mutants N75G/ N175Q (DM) and N75G/N175Q/N252Q (TM) were expressed in $P$. pastoris in Infors HT Multifors bioreactors in parallel and in three repeats to compare expression efficiency (Fig. 2). Due to limitations in the aeration with pressurised air, oxygen supply was limited in the bioreactors and a methanol feed rate of $0.4 \mathrm{~mL} \mathrm{~h}^{-1}$ could not be exceeded. There was no significant difference in the protein concentration in the supernatant between wild type and mutant $\mathrm{PDH}$ producers after $96 \mathrm{~h}$. AmPDH1 N75G showed a similar volumetric activity yield as that of the wild type, whereas AmPDH1 DM and TM had a lower 


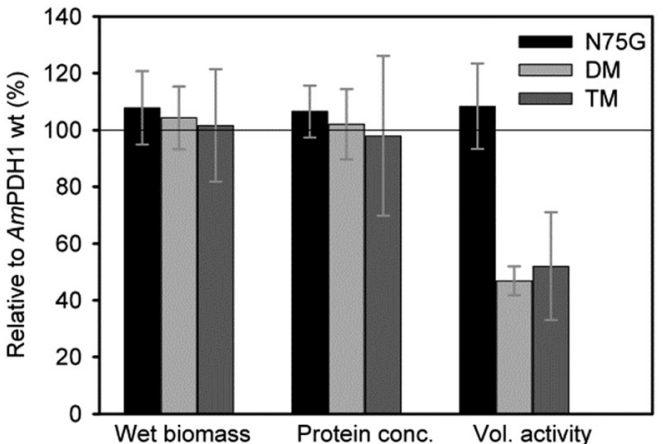

Fig. 2 Recombinant expression of AmPDH1 N75G, DM, TM and wt in $P$. pastoris in Infors Multifors bioreactor: wet biomass, protein concentration and volumetric activity after $96 \mathrm{~h}$ relative to the wild type reference.

volumetric activity yield of $\sim 50 \%$ of that of the wild type (Fig. 2).

The not optimised expression yielded 0.1-0.4 $\mathrm{U} \mathrm{mL}^{-1}$ (0.3-3.7 $\mathrm{U} \mathrm{mg}^{-1}$ ) in the supernatant. Purification was done by a 3-step chromatography scheme (Phenyl-Sepharose, DEAESepharose, Phenyl-Source), whereas AmPDH1 DM was polished in an additional gel filtration step with Superose12 resin (Table S3, $\mathrm{ESI} \dagger$ ). An eight- to 115 -fold increase in specific activity could be achieved with a purification yield of $11-30 \%$, due to strict pooling. In parallel production experiments of mutant enzymes with wild type enzyme, the single mutation N75G had no significant impact on expression efficiency. The mutation at $\mathrm{N}^{175}$ in AmPDH1 DM, however, decreased the volumetric and specific yield by half. An additional mutation at $\mathrm{N}^{252}$ in $A m \mathrm{PDH} 1 \mathrm{TM}$ did not lead to a further decrease in yield. The single mutation N175Q showed an ambiguous picture with expression levels between wt/N75G and AmPDH1 DM (data not shown). This suggests a different importance of the particular glycosylation sites, in this case namely that position $\mathrm{N}^{175}$ requires intact $N$-glycosylation for proper folding and/ or secretion of the enzyme. AmPDH1 N175Q, DM and TM showed sufficient expression levels in $5 \mathrm{~L}$ stirred-tank bioreactors and AmPDH1 N75G in shake flasks $\left(0.1-0.4 \mathrm{U} \mathrm{mL}^{-1}\right)$ for subsequent characterisation of the purified enzyme.

\section{Protein characterisation}

The fragmentation of purified AmPDH1 into a $\sim 46 \mathrm{kDa}$ and a $\sim 20 \mathrm{kDa}$ fragment (observed on SDS-PAGE) was described by Sygmund et al. ${ }^{36}$ Yakovleva et al. ${ }^{35}$ observed complete fragmentation of enzymatically deglycosylated AmPDH1 (dgAmPDH1) within 2 months at $4{ }^{\circ} \mathrm{C}$, with a concomitant $\sim 6$-fold increase in specific activity. All tested AmPDH1 $N$-glycosylation mutants also formed these two fragments in a glycosylation-dependent pattern (Fig. S1, ESI $\dagger$ ). AmPDH1 DM and TM were fragmented to a large degree immediately after purification, and completely within 1-2 months, and showed an increase in specific activity similar to dgAmPDH1. AmPDH1 N175Q fragmentation was slower with a less pronounced activity increase, and $A m \mathrm{PDH} 1$ wt and N75G only started to fragment in this time frame without any increase in specific activity. As observed for expression efficiency, there is no significant effect by the mutation of $\mathrm{N}^{75}$ alone, a larger influence of $\mathrm{N}^{175}$ alone, and a significant effect to levels observed for dgAmPDH1 by a combination of these two mutations. A third mutation, eliminating the distant site 252 , does not increase any of the observed effects further. Therefore, the $\mathrm{N}$-glycosylation sites in proximity to the active site appear to influence correct folding and expression/secretion efficiency. The mechanism of cleavage at $\mathrm{S} 416 / \mathrm{Y} 417$ is not known and appears to be a spontaneous or autocatalytic process, as it is observed in protein preparations that are purified to homogeneity. It has to be noted that, despite the appearance of two distinct fragments originating from the same protein on SDS-PAGE (confirmed by peptide sequencing, not shown), an actual separation of the two fragments is highly unlikely, if not impossible, as the smaller fragment contains amino acids considered essential to catalysis. ${ }^{47}$ Mass spectrometric investigation of the mutants, including DM and TM, also did not reveal any large missing fragments (not shown). This indicates that the peptide chain is "nicked" upon storage, but the two fragments remain attached to each other, as is suggested by their close interaction (Fig. 1b), and only separate under denaturing conditions. Nevertheless, the presence of glycosyl moieties on the two $N$-glycosylation sites in near vicinity, particularly the closest one, exerts a strong influence. It is also interesting to note that the elimination of one and two glycosylation sites $\left(\mathrm{N}^{75}, \mathrm{~N}^{175}\right.$, or both) does not visibly reduce the molecular mass of the purified protein, suggesting heavier glycosylation of the remaining site(s). Only knock-out of $\mathrm{N}^{75}, \mathrm{~N}^{175}$ and $\mathrm{N}^{252}$ results in a sharp band at $\sim 65 \mathrm{kDa}$ on the SDS-PAGE, indistinguishable from the enzymatically deglycosylated wt AmPDH1.

\section{Electrochemical methods}

All chemicals were purchased from Sigma-Aldrich Chemie GmbH (Steinheim, Germany) if not stated otherwise. Synthesis of osmium redox polymers: $\left[\mathrm{Os}(\mathrm{dmobpy})_{2}(\mathrm{PVI})_{10} \mathrm{Cl}\right]^{+2 /+}\left(E^{\circ \prime}=140 \mathrm{mV} v s\right.$. NHE $)$, $\left[\mathrm{Os}(\mathrm{dmbpy})_{2}(\mathrm{PVI})_{10} \mathrm{Cl}\right]^{+2 /+}\left(E^{\circ \prime}=320 \mathrm{mV}\right.$ vs. NHE $)$ and $\left[\mathrm{Os}(\mathrm{bpy})_{2^{-}}\right.$ $\left.(\mathrm{PVI}){ }_{10} \mathrm{Cl}\right]^{+2 /+}\left(E^{\circ \prime}=420 \mathrm{mV}\right.$ vs. NHE$)$, where dmobpy is $4,4^{\prime}-$ dimethoxy-2,2'-bipyridine, dmbpy is $4,4^{\prime}$-dimethyl-2,2'-bipyridine, bpy is $2,2^{\prime}$-bipyridine, and PVI is poly( $N$-vinylimidazole), was performed according to the protocol described in. ${ }^{48,49}$ The osmium polymers were dissolved in deionised water to obtain a concentration of $5 \mathrm{mg} \mathrm{mL}^{-1}$. Sodium phosphate buffer with a total phosphate concentration of $50 \mathrm{mM}$ (pH 7.4) containing $137 \mathrm{mM}$ $\mathrm{NaCl}$ was used throughout all experiments. It was degassed prior to the measurements in order to avoid bubble formation in the FIA system. Calibration solutions of $\mathrm{D}(+)$-glucose were prepared daily by diluting a $40 \mathrm{mM}$ stock solution with buffer. All aqueous solutions were prepared using deionised water purified with a Milli-Q purification system (EMD Millipore Corporation, Billerica, MA, USA).

\section{Preparation of enzyme-modified graphite electrodes}

The electrodes were prepared from graphite rods with a diameter of $3.05 \mathrm{~mm}$ and $13 \%$ porosity (Ringsdorff Werke GmbH, Bonn, Germany). Rods were cut into $3 \mathrm{~cm}$ pieces, polished on wet emery paper (grit number P1200), washed with water and dried in an air flow prior to modification. For chemical cross-linking 
poly(ethyleneglycol)(400)diglycidyl ether (PEGDGE) was diluted to a final concentration of $68 \%(\mathrm{v} / \mathrm{v})$ with deionised water. Two microliters of PEGDGE solution were then mixed with $5 \mu \mathrm{L}$ of Os-polymer solution on the surface of the graphite electrode and left for $10 \mathrm{~min}$ before drop-coating of the enzyme. Five microliter of each enzyme solution (N75G: $26.3 \mathrm{mg} \mathrm{mL}^{-1}$ / $1440 \mathrm{U} \mathrm{mL} \mathrm{m}^{-1}$; N175Q: $24.1 \mathrm{mg} \mathrm{mL} \mathrm{m}^{-1} / 1103 \mathrm{U} \mathrm{mL}^{-1}$; DM: $17.0 \mathrm{mg} \mathrm{mL}^{-1} / 624 \mathrm{U} \mathrm{mL}^{-1}$; TM: $16.1 \mathrm{mg} \mathrm{mL}^{-1} / 820 \mathrm{U} \mathrm{mL}^{-1}$ ) were added to the mixture of PEGDGE-Os-polymer and left overnight at $4{ }^{\circ} \mathrm{C}$ in a humid atmosphere for completion of cross-linking. For direct electron transfer (DET) experiments $5 \mu \mathrm{L}$ of solutions containing the various mPDHs were directly drop-coated onto the surface of working electrodes and stored overnight under the same conditions as described for mediated electron transfer (MET). The modified electrodes were rinsed with the running buffer prior to the measurements in order to remove loosely attached material. All experiments were performed at room temperature.

\section{Flow-injection amperometry}

The current response of the enzyme-modified electrodes towards the substrate (glucose) was measured using a flow-injection (FI) system described elsewhere. ${ }^{50,51}$ The electrodes were pressfitted into a teflon holder and mounted into a wall-jet type flow-through electrochemical cell. ${ }^{52}$ The graphite rods served as the working electrode, an $\mathrm{Ag} \mid \mathrm{AgCl}(0.1 \mathrm{M} \mathrm{KCl}, 288 \mathrm{mV}$ vs. NHE$)$ as the reference electrode and a platinum wire as the counter electrode. A constant potential was applied onto the working electrode controlled by a three-electrode potentiostat (Zäta Electronics, Höör, Sweden). Glucose solutions of different concentrations (50 $\mu \mathrm{l}$ volume) were introduced into the system by a six-port injection valve (Rheodyne, type 7125 LabPR, Cotati, CA, USA) at a constant flow rate of $0.5 \mathrm{~mL} \mathrm{~min}{ }^{-1}$ controlled by a peristaltic pump (Minipuls 3, Gilson, Villier-le Bel, France). The change in current was then registered with a BD 112 recorder (Kipp \& Zonen, Utrecht, The Netherlands). The concentrations of all injected samples were corrected for a dispersion factor of the FI system equal to 1.08. Values for the apparent Michaelis-Menten constant $\left(K_{\mathrm{M}}^{\mathrm{app}}\right)$ and saturating current densities $\left(J_{\max }\right)$ were obtained by fitting the data with the Michaelis-Menten equation.

\section{Cyclic voltammetry}

All voltammograms were recorded using a BAS CV-50W potentiostat (Bioanalytical Systems, West Lafayette, IN, USA) in $50 \mathrm{mM}$ phosphate buffer at pH 7.4 (137 mM NaCl) at room temperature in the absence of oxygen. The response to $25 \mathrm{mM}$ glucose was measured with the enzyme-modified graphite electrodes at a scan rate of 1 or $5 \mathrm{mV} \mathrm{s}^{-1}$. A saturated calomel electrode ( $244 \mathrm{mV} v s$. NHE) was used as the reference electrode and a platinum foil as the counter electrode.

\section{Results and discussion}

\section{Catalytic performance of Os-polymer/mPDH-modified electrodes}

In our recently reported study the glycosylation positions in PDH were assigned using MALDI-MS in combination with Endo
$\mathrm{H}$ treatment and tryptic digestion. ${ }^{35}$ The obtained information was used for production of the mPDHs lacking part of the glycosylation. This was accomplished by destroying a typical glycosylation pattern $N-\mathrm{X}-\mathrm{S} / \mathrm{T} / \mathrm{C}$ (where X can be any amino acid except for proline ${ }^{53}$ ) in the protein polypeptide chain. $\mathrm{N}$ in the tripeptide consensus sequon was exchanged to either $\mathrm{G}$ or $\mathrm{Q}$ and two single, one double and one triple $\mathrm{MPDH}$ with different degrees of deglycosylation were engineered. The study of the use of these enzymes focuses on their bioelectrochemical characterisation when co-immobilised with the polyvinylimidazolebound Os-complexes exhibiting different $E^{\circ \prime}$-values defined by the electron donating/accepting radical in the $4,4^{\prime}$-position of the $2,2^{\prime}$ bipyridine ligands of the polymer. ${ }^{48}$ For provision of anodes for EBFCs, redox polymers demonstrating glucose oxidation at lower redox potentials provide the possibility of power production at higher overall cell voltages. ${ }^{54,55}$ However, this advantage may be offset by the loss in catalysis as the redox potential approaches the potential of the PDH active site. ${ }^{18}$ The applied potential for characterisation of the mediator/enzyme couples was selected based on previously reported data. ${ }^{30-32,35,43}$ Os(dmobpy)PVI/mPDHmodified electrodes were characterised at an applied potential of $288 \mathrm{mV} v s$. NHE, at which a steady state current is obtained. An applied potential of $444 \mathrm{mV} v s$. NHE was selected for electrodes coated with Os(dmbpy)PVI/mPDH and Os(bpy)PVI/mPDH.

The electrocatalytic response of the films containing the different Os-polymer/mPDHs couples to glucose were measured in the flow injection system in $50 \mathrm{mM}$ phosphate buffer $\mathrm{pH} 7.4$ (137 mM NaCl) (Fig. S2, ESI $\dagger$ ). The current densities obtained for the oxidation of glucose by the mPDHs-containing films increase with a shift in $E^{\circ \prime}$-values of the Os-polymer towards more positive values as a function of the ligand used: Os(dmobpy)PVI < Os(dmbpy)PVI < Os(bpy)PVI (Table 1).

This result is expected considering that the driving force for electron transfer is increasing with the increase in potential difference between the bound FAD of $\mathrm{MPDH}$ and the Os-polymer. Maximum response is obtained for each of the mPDHs electrochemically "wired" with the Os(bpy)PVI-based polymer. The $K_{\mathrm{M}}^{\mathrm{app}}$-values obtained from the curve fitting of the results are displayed in Table 1 and the smallest $K_{\mathrm{M}}^{\mathrm{app}}$-values are obtained for the electrodes containing mPDH "wired" to the Os(dmobpy)PVI polymer exhibiting the lowest $E^{\circ \prime}$.

The CVs recorded in the absence of substrate (Fig. 3) indicate that films of the DM and TM enzyme contain approximately half the amount of redox-active polymer compared to films of the N75G and N175Q enzyme, whilst providing higher maximum current densities (Table 1). Osmium coverage alone therefore does not determine glucose oxidation current response. The cyclic voltammetry results presented in Fig. 3 are in a good agreement with the FIA data (Fig. S2, ESI $\dagger$ ).

When comparing the various mPDHs a clear correlation between the electrocatalytic response and the degree of deglycosylation can be observed for the SMs and the DM (Fig. 3 and Fig. S2, ESI $\dagger$ ). The DM co-immobilised with the different Os-polymers generates current densities greater than those obtained for either of the SMs covalently bound to the corresponding Os-polymers. The concentration in terms of $\mathrm{mg} \mathrm{mL}^{-1}$ 
Table 1 Summary of kinetic data obtained in the flow mode using Os-polymer/mPDH-and mPDH-modified electrodes

\begin{tabular}{|c|c|c|c|c|c|}
\hline \multirow[b]{2}{*}{$\mathrm{mPDH}$} & \multirow{2}{*}{$\frac{\text { Type of } \mathrm{ET}^{a}}{\text { Kin. param. }^{b}}$} & \multicolumn{3}{|l|}{ MET } & \multirow[b]{2}{*}{ DET } \\
\hline & & Os(dmobpy)-PVI & Os(dmbpy)-PVI & Os(bpy)-PVI & \\
\hline N75G & $J_{\max } / \mu \mathrm{A} \mathrm{cm}{ }^{-2}$ & $0.5 \pm 0.02$ & $2.5 \pm 0.09$ & $22.2 \pm 1.8$ & $1 \pm 0.06$ \\
\hline DM & & $9.8 \pm 0.3$ & $290.1 \pm 15.9$ & $802.4 \pm 101.07$ & $7.8 \pm 0.7$ \\
\hline $\mathrm{TM}$ & & $35.2 \pm 0.5$ & $51.7 \pm 0.6$ & $215 \pm 2.5$ & $6.6 \pm 0.2$ \\
\hline N75G & $K_{\mathrm{M}}^{\mathrm{app}} / \mathrm{mM}$ & $1.9 \pm 0.1$ & $5.9 \pm 0.2$ & $6.7 \pm 0.1$ & $4.5 \pm 0.4$ \\
\hline $\mathrm{TM}$ & & $0.7 \pm 0.1$ & $4.4 \pm 0.6$ & $10.2 \pm 2.4$ & $3.9 \pm 0.9$ \\
\hline
\end{tabular}

is higher for the SMs (N75 g: $26.3 \mathrm{mg} \mathrm{mL}^{-1}$; N175Q: $24.1 \mathrm{mg} \mathrm{mL}^{-1}$ ) than for the DM $\left(17.0 \mathrm{mg} \mathrm{mL}^{-1}\right)$ and the TM $\left(16.1 \mathrm{mg} \mathrm{mL}^{-1}\right)$. Even though the specific activity of the enzyme solutions (N75G: 1440 $\mathrm{U} \mathrm{mL}^{-1}$; N175Q: $1103 \mathrm{U} \mathrm{mL}^{-1}$; DM: $624 \mathrm{U} \mathrm{mL}^{-1}$; TM: $820 \mathrm{U} \mathrm{mL}^{-1}$ ) is around twice as high for the SMs, the current densities obtained for the oxidation of glucose increase in the following order: N75 < N175 < DM (Table 1). The explanation may be that the electron transfer rate between the two electroactive species is increased by bringing them closer to each other. ${ }^{23}$ The glycan shell of DM is smaller than that of the SMs. Therefore, the active site of the DM is more accessible to be "wired" to the Os-polymer compared to mPDHs with a higher glycosylation degree and the electron transfer will hence become faster.

Taking these observations into consideration, it is expected that the TM should outperform both the DM and the SMs when "wired" with the various Os-polymers, because the TM has less carbohydrates attached to its polypeptide chain. Surprisingly,

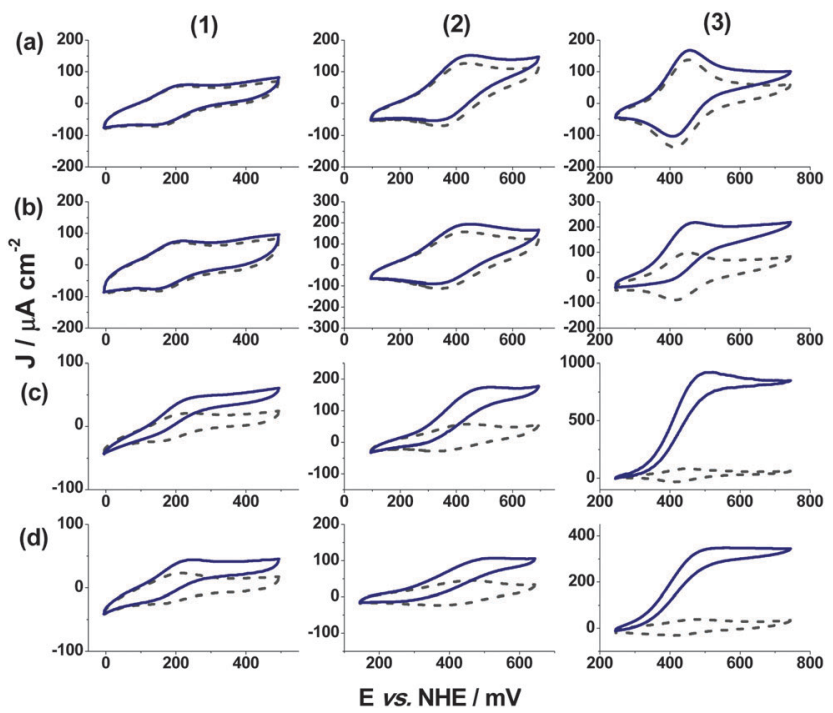

Fig. 3 Cyclic voltammograms of a series of Os-polymer/mPDH-dropcoated graphite electrodes recorded at a scan rate of $1 \mathrm{mV} \mathrm{s}^{-1}$ in $50 \mathrm{mM}$ phosphate buffer (137 mM NaCl, pH 7.4) in inert atmosphere in (grey dotted line) the absence and (blue solid line) the presence of $25 \mathrm{mM}$ glucose: (a) N75G-; (b) N175Q-; (c) DM-; (d) TM-modified electrodes. Os-polymers used for cross-linking with various mPDHs: (1) Os(dmobpy)PVI-; (2) Os(dmbpy)PVI-; (3) Os(bpy)PVI-based polymer. the opposite effect is observed. Analysis of the biological functions of carbohydrates indicates that the latter play an important role in the physical maintenance and the catalytic performance of the whole glycoprotein. Moreover, it is difficult to predict a priori an effect of elimination of the glycan on the properties of the glycoprotein. ${ }^{56}$ This may explain why the DM shows much better catalytic response to glucose compared to the TM in both flow injection and cyclic voltammetric measurements, when the same mass of enzymes is co-immobilised with the mediator on the surface of the working electrodes. Apparently, glycosylation in $\mathrm{N}^{252}$ is needed for retaining a high activity of mPDH using the osmium polymers as mediators, and exchanging $\mathrm{N}$ to $\mathrm{Q}$ in the protein polypeptide chain does not further improve the catalytic efficiency of $\mathrm{mPDH}$.

The onset of the oxidation current is observed for all of the enzyme electrodes starting at a potential close to the $E^{\circ \prime}$ of each redox polymer. The films modified with cross-linked Os(bpy)PVI/DM display the highest current densities (Table 1) compared to the other mPDHs prepared using the same redox polymer. With an increase in $E^{o \prime}$ of the mediator the catalytic response of the Os-polymer/mPDHmodified electrodes becomes more clearly observed in the cyclic voltammograms, as expected considering the increase in the thermodynamic driving force of the electron transfer reaction.

The performance of the Os(dmbpy)PVI/DM electrode exhibiting the highest response to glucose in the FI and the CV studies was compared with the previously reported data on films prepared by co-immobilisation of an Os-polymer with enzymatically deglycosylated recombinantly expressed $A m \mathrm{PDH}(\mathrm{dgPDH})^{31,32}$ or the more active fragmented form of the same enzyme (fdgPDH). ${ }^{35}$ Equal mass amounts of the enzyme, mediator and cross-linker were utilised for drop-coating onto the electrodes and the obtained films were screened under similar experimental conditions (buffer composition, applied potential, glucose as a substrate). The Os(dmbpy)PVI/DM-based films reported here produce a higher catalytic response $\left.\left(J_{\max }=290 \mu \mathrm{A} \mathrm{cm}\right)^{-2}\right)$ compared to the $J_{\max }$ of $146 \mu \mathrm{A} \mathrm{cm}^{-2}$ and $248 \mu \mathrm{A} \mathrm{cm}^{-2}$ for the Os(dmbpy)PVI/dgPDH- and the Os(dmbpy)PVI/fdgPDH-based films, respectively. ${ }^{32,35}$

Comparison with results of other sugar-oxidising enzyme electrodes is difficult due not only to considerable differences in the testing conditions such as glucose concentration, temperature and $\mathrm{pH}$ selected, but also to the effect of the electrode preparation methodologies, variability in experimental approaches and the 
method used to measure current density. For example, Murata et al. ${ }^{57}$ recently reported that deglycosylated FAD-dependent glucose dehydrogenase from Aspergillus terreus, co-immobilised, through diepoxide crosslinking with an Os-polymer on glassy carbon electrodes, rotated at $5000 \mathrm{rpm}$, yields glucose oxidation current densities of 0.95 $\mathrm{mA} \mathrm{cm}{ }^{-2}$ and $4 \mathrm{~mA} \mathrm{~cm}^{-2}$ in $5 \mathrm{mM}$ and $200 \mathrm{mM}$ glucose, respectively, at $0.5 \mathrm{~V}$ vs. $\mathrm{Ag} \mid \mathrm{AgCl}$ in $\mathrm{pH} 7.0$ buffered solution at $25{ }^{\circ} \mathrm{C}$.

Due to the drawbacks associated with general use of mediators, $^{2,3,9}$ DET approach for construction of bioanodes and cathodes is quite appealing. In the present study current output from mPDH-modified electrodes was studied using CV and FI (see ESI $\dagger$ ). Although all of the films containing mPDHs possess an ability to directly communicate with the electrode surface, DET takes place at high overpotentials and current densities produced are much lower in comparison with the MET mode (Fig. S3 and S4, ESI $\dagger$ ). Therefore, application of mPDH-modified films in fabrication of bioanodes is still limited.

\section{Conclusions}

A number of recombinantly expressed mPDHs with different degrees of glycosylation produced by site-directed mutagenesis are screened in order to select the mutant enzyme exhibiting properties required for further application in the fabrication of bioanodes. The enzymes are co-immobilised with Os(dmobpy)PVI, Os(dmbpy)PVI and Os(bpy)PVI-based redox polymers ranging in $E^{\circ \prime}$ and co-precipitated on the surface of graphite working electrodes. An equal mass of all film components is utilised for electrode preparation and comparison. The Os-polymer/mPDH-modified film electrodes are characterised using flow-injection amperometry and CV. The Os(bpy)PVI/DM-based films reported here produce the higher catalytic response $\left(J_{\max }=802 \mu \mathrm{A} \mathrm{cm}^{-2}\right.$ ) compared to those films prepared using the Os-polymers with a lower $E^{\circ \prime}$ and with a different degree of glycosylation. The greater current densities generated by those biocatalytic films containing DM co-immobilised with Os(bpy)PVI and the less laborious and relatively fast production of the enzyme makes it easier to integrate the enzyme into an EBFC.

All forms of the mutant enzyme possess an ability to directly communicate with the electrode surface with DM having the highest and the most stable current response to glucose $\left(J_{\max }=7.8 \mu \mathrm{A} \mathrm{cm}^{-2}\right)$.

\section{Acknowledgements}

The following agencies are acknowledged for financial support: CKP, The Austrian Science Fund FWF (grant TRP218); CG, The Austrian Science Fund FWF (CG is a member of the doctoral program Biomolecular Technology of Proteins, grant W1224); LG and MY, The Swedish Research Council, grant 2010-5031: LG and DL The European Commission "Bioenergy" FP7-PEOPLE2013-ITN-607793.

\section{References}

1 S. C. Barton, J. Gallaway and P. Atanassov, Chem. Rev., 2004, 104, 4867-4886.
2 M. T. Meredith and S. D. Minteer, in Annual Review of Analytical Chemistry, ed. R. G. Cooks and E. S. Yeung, Annual Reviews, Palo Alto, 2012, vol. 5, pp. 157-179.

3 D. Leech, P. Kavanagh and W. Schuhmann, Electrochim. Acta, 2012, 84, 223-234.

4 Y. Liu, Y. Du and C. M. Li, Electroanalysis, 2013, 25, 815-831.

5 Y. Song, V. Penmasta and C. Wang, in Biofuel's Engineering Process Technology, ed. M. A. D. S. Bernardes, 2011, ch. 28, pp. 657-684.

6 S. A. Neto, J. C. Forti and A. R. De Andrade, Electrocatalysis, 2010, 1, 87-94.

7 P. Kavanagh and D. Leech, Phys. Chem. Chem. Phys., 2013, 15, 4859-4869.

8 M. Falk, C. W. Narváez Villarrubia, S. Babanova, P. Atanassov and S. Shleev, ChemPhysChem, 2013, 14, 2045-2058.

9 M. Falk, Z. Blum and S. Shleev, Electrochim. Acta, 2012, 82, 191-202.

10 W. Greatbatch and C. F. Holmes, Pacing Clin. Electrophysiol., 1992, 15, 2034-2036.

11 N. Mano, Chem. Commun., 2008, 2221-2223.

12 A. Heller, J. Phys. Chem., 1992, 96, 3579-3587.

13 A. Heller, Phys. Chem. Chem. Phys., 2004, 6, 209-216.

14 A. Heller, Curr. Opin. Chem. Biol., 2006, 10, 664-672.

15 A. Heller, Anal. Bioanal. Chem., 2006, 385, 469-473.

16 A. Heller and B. Feldman, Chem. Rev., 2008, 108, 2482-2505.

17 D. MacAodha, P. ÓConghaile, B. Egan, P. Kavanagh, C. Sygmund, R. Ludwig and D. Leech, Electroanalysis, 2013, 25, 94-100.

18 F. Tasca, L. Gorton, M. Kujawa, I. Patel, W. Harreither, C. K. Peterbauer, R. Ludwig and G. Nöll, Biosens. Bioelectron., 2010, 25, 1710-1716.

19 F. Tasca, L. Gorton, W. Harreither, D. Haltrich, R. Ludwig and G. Nöll, J. Phys. Chem. C, 2008, 112, 13668-13673.

20 F. Barriere, P. Kavanagh and D. Leech, Electrochim. Acta, 2006, 51, 5187-5192.

21 P. Kavanagh, S. Boland, P. Jenkins and D. Leech, Fuel Cells, 2009, 9, 79-84.

22 O. Courjean, V. Flexer, A. Prévoteau, E. Suraniti and N. Mano, ChemPhysChem, 2010, 11, 2795-2797.

23 R. A. Marcus and N. Sutin, Biochim. Biophys. Acta, 1985, 811, 265-322.

24 E. E. Ferapontova, V. G. Grigorenko, A. M. Egorov, T. Börchers, T. Ruzgas and L. Gorton, Biosens. Bioelectron., 2001, 16, 147-157.

25 A. Lindgren, M. Tanaka, T. Ruzgas, L. Gorton, I. Gazaryan, K. Ishimori and I. Morishima, Electrochem. Commun., 1999, 1, 171-175.

26 S. Demin and E. A. H. Hall, Bioelectrochemistry, 2009, 76, 19-27.

27 A. Prévoteau, O. Courjean and N. Mano, Electrochem. Commun., 2010, 12, 213-215.

28 R. Ortiz, H. Matsumura, F. Tasca, K. Zahma, M. Samejima, K. Igarashi, R. Ludwig and L. Gorton, Anal. Chem., 2012, 84, 10315-10323.

29 S. C. Feifel, R. Ludwig, L. Gorton and F. Lisdat, Langmuir, 2012, 28, 9189-9194. 
30 M. E. Yakovleva, A. Killyéni, R. Ortiz, C. Schulz, D. MacAodha, P. ÓConghaile, D. Leech, I. C. Popescu, C. Gonaus, C. K. Peterbauer and L. Gorton, Electrochem. Commun., 2012, 24, 120-122.

31 A. Killyéni, M. E. Yakovleva, D. MacAodha, P. ÓConghaile, C. Gonaus, R. Ortiz, D. Leech, I. C. Popescu, C. K. Peterbauer and L. Gorton, Electrochim. Acta, 2014, 126, 61-67.

32 A. Killyéni, M. E. Yakovleva, C. K. Peterbauer, D. Leech, L. Gorton and I. C. Popescu, Stud. Univ. Babes-Bolyai, Chem., 2012, 57, 87-99.

33 M. Shao, M. N. Zafar, C. Sygmund, D. A. Guschin, R. Ludwig, C. K. Peterbauer, W. Schuhmann and L. Gorton, Biosens. Bioelectron., 2013, 40, 308-314.

34 M. Shao, M. N. Zafar, M. Falk, R. Ludwig, C. Sygmund, C. K. Peterbauer, D. A. Guschin, D. MacAodha, P. ÓConghaile, D. Leech, M. D. Toscano, S. Shleev, W. Schuhmann and L. Gorton, ChemPhysChem, 2013, 14, 2260-2269.

35 M. E. Yakovleva, A. Killyéni, O. Seubert, P. ÓConghaile, D. MacAodha, D. Leech, C. Gonaus, I. C. Popescu, C. K. Peterbauer, S. Kjellström and L. Gorton, Anal. Chem., 2013, 85, 9852-9858.

36 C. Sygmund, R. Kittl, J. Volc, P. Halada, E. Kubátová, D. Haltrich and C. K. Peterbauer, J. Biotechnol., 2008, 133, 334-342.

37 D. R. Cavener, J. Mol. Biol., 1992, 223, 811-814.

38 C. K. Peterbauer and J. Volc, Appl. Microbiol. Biotechnol., 2010, 85, 837-848.

39 W. Harreither, C. Sygmund, M. Augustin, M. Narciso, M. L. Rabinovich, L. Gorton, D. Haltrich and R. Ludwig, Appl. Environ. Microbiol., 2011, 77, 1804-1815.

40 R. Ludwig, W. Harreither, F. Tasca and L. Gorton, ChemPhysChem, 2010, 11, 2674-2697.

41 R. Baron, C. Riley, P. Chenprakhon, K. Thotsaporn, R. T. Winter, A. Alfieri, F. Forneris, W. J. H. van Berkel, P. Chaiyen, M. W. Fraaije, A. Mattevi and J. A. McCammon, Proc. Natl. Acad. Sci. U. S. A., 2009, 106, 10603-10608.
42 T. C. Tan, O. Spadiut, T. Wongnate, J. Sucharitakul, I. Krondorfer, C. Sygmund, D. Haltrich, P. Chaiyen, C. K. Peterbauer and C. Divne, PLoS One, 2013, 8, e53567.

43 M. N. Zafar, F. Tasca, S. Boland, M. Kujawa, I. Patel, C. K. Peterbauer, D. Leech and L. Gorton, Bioelectrochemistry, 2010, 80, 38-42.

44 I. Pisanelli, M. Kujawa, D. Gschnitzer, O. Spadiut, B. Seiboth and C. Peterbauer, Appl. Microbiol. Biotechnol., 2010, 86, 599-606.

45 M. Kujawa, J. Volc, P. Halada, P. Sedmera, C. Divne, C. Sygmund, C. Leitner, C. Peterbauer and D. Haltrich, FEBS J., 2007, 274, 879-894.

46 R. Kittl, C. Sygmund, P. Halada, J. Volc, C. Divne, D. Haltrich and C. K. Peterbauer, Curr. Genet., 2008, 53, 117-127.

47 I. Krondorfer, K. Lipp, D. Brugger, P. Staudigl, C. Sygmund, D. Haltrich and C. K. Peterbauer, PLoS One, 2014, 9, e91145.

48 R. J. Forster and J. G. Vos, Macromolecules, 1990, 23, 4372-4377.

49 E. M. Kober, J. V. Caspar, B. P. Sullivan and T. J. Meyer, Inorg. Chem., 1988, 27, 4587-4598.

50 J. Ṙužička and E. H. Hansen, Anal. Chim. Acta, 1975, 78, 145-157.

51 K. Štulík and P. Pacáková, Electroanalytical Measurements in Flowing Liquids, John Wiley and Sons, New York, 1987.

52 R. Appelqvist, G. Marko-Varga, L. Gorton, A. Torstensson and G. Johansson, Anal. Chim. Acta, 1985, 169, 237-247.

53 E. Bause, Biochem. J., 1983, 209, 331-336.

54 P. ÓConghaile, D. MacAodha, B. Egan, P. Kavanagh and D. Leech, J. Electrochem. Soc., 2013, 160, G3165-G3170.

55 D. MacAodha, P. ÓConghaile, B. Egan, P. Kavanagh and D. Leech, ChemPhysChem, 2013, 14, 2302-2307.

56 A. Varki, Glycobiology, 1993, 3, 97-130.

57 K. Murata, W. Akatsuka, T. Sadakane, A. Matsunaga and S. Tsujimura, Electrochim. Acta, 2014, 136, 537-541. 